\title{
Towards better management of Australia's shark fishery: genetic analyses reveal unexpected ratios of cryptic blacktip species Carcharhinus tilstoni and C. limbatus
}

\author{
J. R. Ovenden ${ }^{\mathrm{A}, \mathrm{C}}$, J. A. T. Morgan ${ }^{\mathrm{A}}$, T. Kashiwagi ${ }^{\mathrm{A}}$, D. Broderick ${ }^{\mathrm{A}}$ and J. Salini ${ }^{\mathrm{B}}$ \\ A Molecular Fisheries Laboratory, Queensland Primary Industries and Fisheries, \\ PO Box 6097, St Lucia, QLD 4069, Australia. \\ ${ }^{B}$ CSIRO Marine Laboratories, Cleveland, QLD 4163, Australia. \\ ${ }^{\mathrm{C}}$ Corresponding author. Email: jennifer.ovenden@dpi.qld.gov.au
}

\begin{abstract}
The common blacktip shark (Carcharhinus limbatus) and the Australian blacktip shark (C. tilstoni) are morphologically similar species that co-occur in subtropical and tropical Australia. In striking contrast to what has been previously reported, we demonstrate that the common blacktip shark is not rare in northern Australia but occurs in approximately equal frequencies with the Australian blacktip shark. Management of shark resources in northern Australia needs to take account of this new information. Species identification was performed using nucleotide sequences of the control, NADH dehydrogenase subunit 4 (ND4) and cytochrome oxidase I (COI) regions in the mitochondrial genome. The proportion of overall genetic variation $\left(F_{\mathrm{ST}}\right)$ between the two species was small $(0.042, P<0.01)$ based on allele frequencies at five microsatellite loci. We confirm that a third blacktip species (C. amblyrhynchoides, graceful shark) is closely related to $C$. tilstoni and $C$. limbatus and can be distinguished from them on the basis of mtDNA sequences from two gene regions. The Australian blacktip shark (C. tilstoni) was not encountered among 20 samples from central Indonesia that were later confirmed to be common blacktip and graceful sharks. Fisheries regulators urgently need new information on life history, population structure and morphological characters for species identification of blacktip shark species in Australia.
\end{abstract}

Additional keywords: blacktip shark, COI, control region, cytochrome oxidase I, fisheries, Indonesia, NADH dehydrogenase subunit 4, ND4, species identification.

\section{Introduction}

Species are the basic unit for the sustainable management and conservation of biodiversity (Lindenmayer and Burgman 2005; King 2007). Species taxonomy is important because it shapes public recognition of biodiversity (Lindenmayer and Burgman 2005), which drives the processes of ecosystem and biological resource management in the public and private sector. In fisheries science, species are largely distinguished morphologically with the expectation of taxonomic congruence across other data types. DNA-based data can be used to test morphologically defined species and can provide new tools for species identification.

There are 322 chondrichthyan species currently recognised in Australia (182 sharks, 125 rays and 15 chimaeras or ghostsharks), which represents about one-third of worldwide chondrichthyan biodiversity. Endemicity in Australia is high (51\%) (Last and Stevens 2009). Whaler sharks (genus Carcharhinus) are a worldwide assemblage of over 30 commercially important species that have largely coastal distributions (Compagno et al. 2005). Twenty-one species occur in Australian waters, predominantly in the tropical north, and two species (Carcharhinus fitzroyensis and C. tilstoni) are endemic to Australia (Last and Stevens 2009).
The Australian blacktip shark (C. tilstoni) was described by Whitley (1950) and co-occurs in northern Australia with the common blacktip shark ( $C$. limbatus). Carcharhinus tilstoni is endemic to northern Australia and C. limbatus is found in subtropical and tropical waters worldwide (Last and Stevens 2009). There are no known external morphological characters for distinguishing the species (Compagno et al. 2005), but among specimens examined to date, $C$. tilstoni has 84-91 pre-caudal vertebrae while $C$. limbatus has 94-101 (Last and Stevens 2009). Phylogenetic analyses by Lavery (1992) using allozyme characters and by Ward et al. (2008) using DNA characters grouped $C$. tilstoni and $C$. limbatus with the graceful shark (C. amblyrhynchoides).

Blacktip (C. tilstoni and C. limbatus) and other shark species support a commercial fishery across northern Australia. Carcharhinus limbatus is also part of the elasmobranch fishery in south-eastern Asia (White et al. 2006). Like most marine predatory species, sharks are vulnerable to overexploitation. They have naturally low abundance, fecundity that is orders of magnitude below most marine finfish species and a susceptibility to capture by gill-nets and long-lines (Last and Stevens 2009). State and national authorities manage the exploitation of blacktip sharks in northern Australia to ensure that the stock sizes 


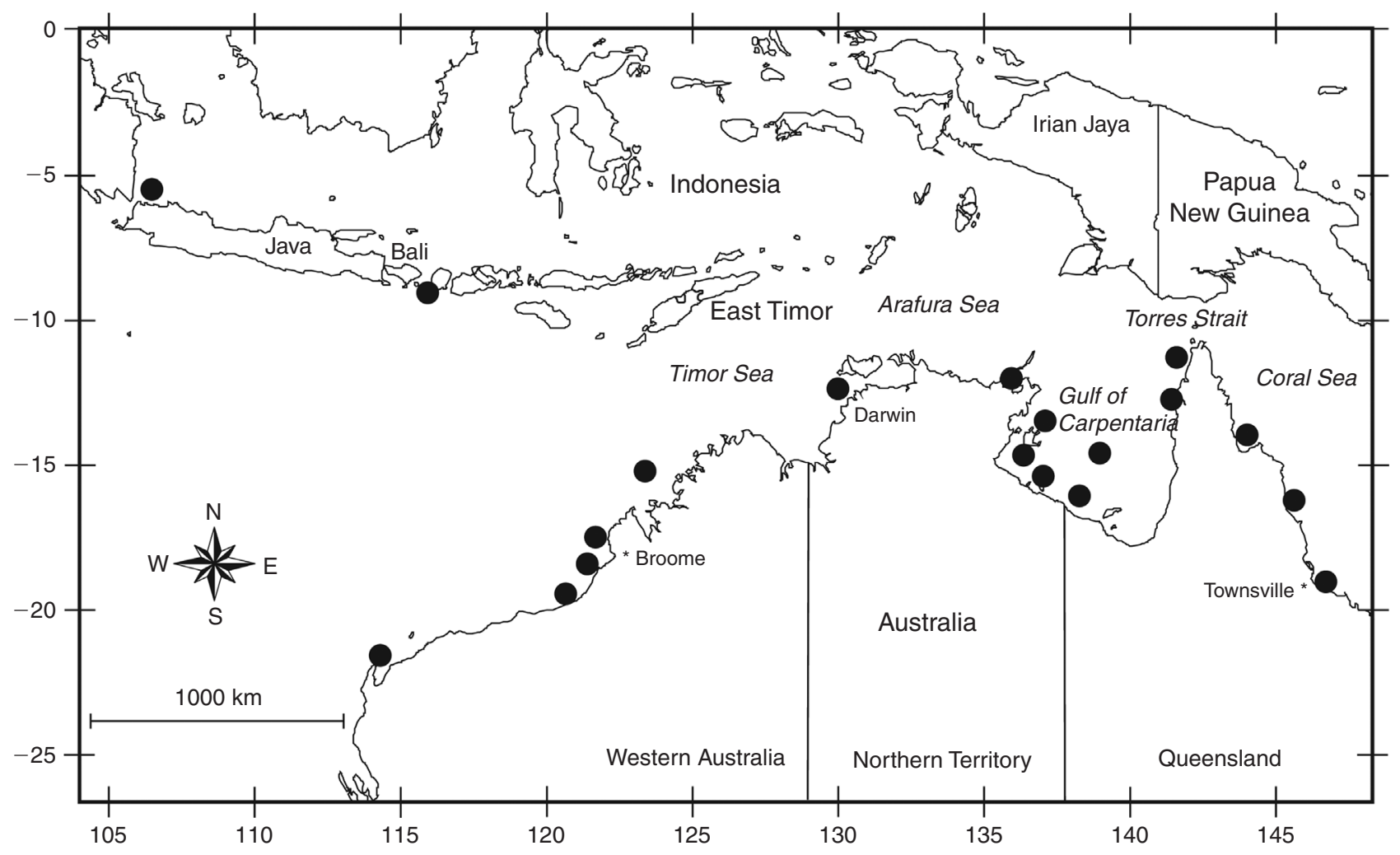

Fig. 1. Collection locations for Carcharhinus tilstoni, C. limbatus and C. amblyrhynchoides from Western Australia, Northern Territory, Queensland and Indonesia.

remain at sustainable levels (Salini et al. 2006). Carcharhinus limbatus is believed to be relatively rare in northern Australia. It was reported as occurring in a $1: 300$ ratio with $C$. tilstoni (Stevens and Wiley 1986) based on 987 C. tilstoni and 20 C. limbatus samples collected from northern Australian waters in 1982 to 1985 for an allozyme genetic study (Lavery and Shaklee 1991). Last and Stevens (2009) stated that $C$. limbatus is a minor component of the commercial harvest in northern Australia.

The present study arose from a population genetic analysis of Australian blacktip sharks, where samples were taken along the northern Australian coastline under the assumption that the majority of blacktip shark would be $C$. tilstoni. However, pilot analyses showed the presence of an additional species, which was identified as $C$. limbatus. Using these blacktip shark samples, we test the assumption that $C$. limbatus is rare in northern Australia using mitochondrial DNA (mtDNA) nucleotide sequence for species identification. Distinctiveness of each species was tested by phylogenetic analysis of mtDNA sequence data in comparison to Australian and Indonesian samples of C. limbatus and C. amblyrhynchoides, and appropriate outgroups. Furthermore, as evolutionary theory predicts that interspecific divergence generally should exceed intraspecific divergence, the proportion of overall genetic variation due to species-level distinction between $C$. tilstoni and $C$. limbatus was estimated using microsatellite loci and compared with intraspecific divergence in a co-occurring species (C. sorrah) from a previous study (Ovenden et al. 2009).

\section{Materials and methods \\ Sample collection}

To assist the development of DNA-based species-identification methods, reference tissue samples were taken from four $C$. limbatus individuals and four C. tilstoni individuals from the north-western Australian coast. Species identification was confirmed in the field by pre-caudal vertebral counts made by R. Pillans and J. Stevens (CSIRO). Counts for C. limbatus ranged from 97 to 100 and were within the accepted range for this species. Counts for $C$. tilstoni samples were 80 to 85 , slightly below the recorded range of 84 to 91 (Last and Stevens 2009). Populations from the west, north and east coasts of Australia (Fig. 1) were sampled to test species composition over a broad spatial scale. Observers and fisheries biologists collected tissue samples from blacktip sharks that they presumed to be C. tilstoni. Pre-caudal vertebral counts were not performed to confirm species identification, except on reference samples.

Carcharhinus amblyrhynchoides and C. limbatus samples were collected from Indonesian markets (Fig. 1) for comparison with Australian samples. The provenance of the Indonesian samples was within $300 \mathrm{~km}$ of markets based on interviews with vendors. Approximately $200 \mathrm{mg}$ of white muscle tissue 
excluding skin was dissected from all specimens and preserved in $1 \mathrm{~mL}$ of a $20 \%$ dimethyl sulfoxide solution (DMSO) in $5 \mathrm{M}$ $\mathrm{NaCl}$. Samples were stored at room temperature in the field and $-70^{\circ} \mathrm{C}$ in the laboratory.

\section{Genomic DNA extraction}

From each sample, $10-50 \mathrm{mg}$ of tissue was digested in $500 \mu \mathrm{L}$ of a suspension of $10 \%$ Chelex-100 (w/v; Biorad Laboratories Inc, Sydney, Australia) in TE buffer ( $5 \mathrm{mM}$ Tris-Cl $\mathrm{pH} 8.0$ with $0.5 \mathrm{mM}$ EDTA). Proteinase $\mathrm{K}(100 \mathrm{ng})$ was added and the tissue was digested to completion at $55^{\circ} \mathrm{C}$ for at least $1 \mathrm{~h}$ on a shaking platform. The mixture was boiled for $5 \mathrm{~min}$ then centrifuged at $13000 \mathrm{~g}$ at room temperature for $5 \mathrm{~min}$ to precipitate the Chelex resin and cellular debris. The supernatant was removed to a fresh tube for subsequent manipulation and storage. A small number of samples were extracted with kits (Wizard, Promega, Madison, WI, USA; DNeasy, Qiagen, Valencia, CA, USA).

\section{Mitochondrial DNA}

To find species-specific DNA markers, the $5^{\prime}$ end of the control region $(\mathrm{CR})$ was amplified and sequenced from 284 blacktip and graceful shark samples. The amplification primers were GWF (CTG CCC TTG GCT CCC AAA GC) and GWR (CTT AGC ATC TTC AGT GCC AT) (Pardini et al. 2001). The internal reverse primer CaR (GGG AAT AGC GAT TTG CTT CA) was designed to obtain a reverse sequence. The NADH dehydrogenase subunit 4 (ND4) region was amplified and sequenced for a subset of 29 samples, which were selected to represent the eight reference samples plus each of the C. tilstoni and C. limbatus control region haplotypes and to maximise geographic spread. ND4 primers were ND4 (CAC CTA TGA CTA CCA AAA GCT CAT GTA GAA GC) (Arevalo et al. 1994) and H12293-LEU (TTG CAC CAA GAG TTT TTG GTT CCT AAG ACC) (Inoue et al. 2001). Cytochrome oxidase subunit I (COI) was also sequenced for the same subset of 29 samples between primers FishF1 (TCA ACC AAC CAC AAA GAC ATT GGC AC) and FishR1 (TAG ACT TCT GGG TGG CCA AAG AAT CA) (Ward et al. 2005).

Amplification reactions for the control region $(50 \mu \mathrm{L}$ reaction volume) contained $1 \times$ PCR buffer (Qiagen), $200 \mu \mathrm{M}$ of each deoxynucleotide triphosphate (dNTP), $1 \mu \mathrm{M}$ of each primer, $2.5 \mathrm{mM}$ of $\mathrm{MgCl}_{2}, 4 \mathrm{U}$ of Taq DNA polymerase (Qiagen) and $10-100 \mathrm{ng}$ of genomic DNA template. Cycling was performed as follows: $90 \mathrm{~s}$ at $94^{\circ} \mathrm{C}$ followed by 35 cycles of $5 \mathrm{~s}$ at $94^{\circ} \mathrm{C}, 30 \mathrm{~s}$ at $55^{\circ} \mathrm{C}$ and $30 \mathrm{~s}$ at $72^{\circ} \mathrm{C}$ with a final extension of $72^{\circ} \mathrm{C}$ for $5 \mathrm{~min}$ (Ovenden et al.2009). Amplifications of the ND4 and COI region $(20 \mu \mathrm{L})$ contained $1 \times$ PCR buffer (Qiagen), $200 \mu \mathrm{M}$ of each dNTP, $0.5 \mu \mathrm{M}$ of each primer, $1.5 \mathrm{mM}$ of $\mathrm{MgCl}_{2}, 1.2 \mathrm{U}$ of $\mathrm{Taq}$ DNA polymerase (Qiagen) and 10-100 ng of genomic DNA template. The cycling conditions were $5 \mathrm{~min}$ at $95^{\circ} \mathrm{C}$ followed by 30 cycles of $15 \mathrm{~s}$ at $95^{\circ} \mathrm{C}, 30 \mathrm{~s}$ at $55^{\circ} \mathrm{C}$ and $1 \mathrm{~min}$ at $72^{\circ} \mathrm{C}$ with a final extension of $72^{\circ} \mathrm{C}$ for $7 \mathrm{~min}$. Cycling was performed in a PTC200 DNA Engine (MJ Research, Waltham, MA, USA). PCR products were viewed on a $1.5 \%$ agarose Tris-acetate-EDTA (TAE) gel stained with GelRed (Biotium Inc., Hayward, CA, USA).

In preparation for sequencing, PCR products were concentrated and desalted using either a QIAquick PCR cleanup kit (Qiagen) or Exosap-it (USB Corporation, Cleveland, OH,
USA). Approximately $20 \mathrm{ng}$ of DNA was used in standard ABI Dye Terminator sequencing reactions and capillary gel separated on an ABI3130XL (Applied Biosystems, Mulgrave, Australia) sequencer. Sequence data was edited and aligned with Sequencher ver. 4.7 (Gene Codes, Ann Arbor, MI, USA) and ClustalX (Thompson et al. 1997). Identical mtDNA sequences were described as haplotypes. Haplotype sequences for C. limbatus were compared with mtDNA control region haplotypes assigned by Keeney and Heist (2006) using GenBank accession numbers AY208861-73 and AY766123-46.

Phylogenetic analysis of mitochondrial DNA sequences was used to examine the pattern of similarity, which would test for species distinctiveness. Sequences were concatenated for phylogenetic analysis following a partition homogeneity test in PAUP* ver. 4.0b10 (Swofford 2002) using only informative sites and 1000 replicates $(P=0.013)$. A significance threshold of 0.01 was used to test for gene congruence as partition homogeneity tests are considered to be conservative (Cunningham 1997). C. dussumieri was included in the alignment as an outgroup. Phylogenetic analyses were carried out using PAUP* ver. 4.0b10 (Swofford 2002). Trees were generated using maximum parsimony (P), maximum likelihood (L) and distance matrix analyses (D). Before constructing $\mathrm{L}$ and $\mathrm{D}$ trees, a model of nucleotide substitution was determined using the Akaike Information Criterion in Modeltest (ver. 3.7, Posada and Crandall 1998). A Tamura-Nei model with among-site heterogeneity was selected (summarised as $\mathrm{TrN}+\mathrm{G}$ ) for the 1902 bases of combined mtDNA control region, COI and ND4 sequences. Model settings used were Lset Base $=(0.2915$ $0.24340 .1316), \mathrm{Nst}=6$, Rmat $=\left(\begin{array}{l}1.00009 .83781 .00001 .0000 \\ \text {. }\end{array}\right.$ 21.4936), Rates $=$ gamma, Shape $=0.1910$ and Pinvar $=0$. Unweighted trees were found using heuristic searches with random sequence addition and tree-bisection-reconnection (TBR) branch swapping.

For the parsimony analysis, gaps were treated as missing data. Other settings used were Mulpars, Maxtrees set to 1000 (P) or 200 (D and L) and heuristic search repetitions set to $1000(\mathrm{P})$ or one (D and L). These settings vary for the different methods of analysis because distance and likelihoodbased analyses are more computationally demanding. Support for nodes was assessed using bootstrap resampling (1000 replicates for $\mathrm{P}$ and D) and Bayesian analysis (B 400000 generations). Bayesian analyses, using posterior probabilities, were completed in MrBayes (Huelsenbeck and Ronquist 2001). A general timereversible + gamma distribution $(\mathrm{GTR}+\mathrm{G})$ substitution model was used for the Bayesian analysis because this was the best approximation of the $\mathrm{TrN}+\mathrm{G}$ model, which was not available within the software package ( $\mathrm{TrN}$ is a restriction of the GTR model). Four chains were run for 500000 generations and the final 400000 trees were used to construct the consensus tree. The burn-in was 100000 . Control region haplotypes were placed in statistical parsimony networks using TCS software (Clement et al. 2000) with parsimony limits of $95 \%$.

\section{Microsatellite loci}

Molecular divergence between and within C. tilstoni and C. limbatus was estimated using microsatellite loci. Allele frequencies for five dinucleotide microsatellite loci (Cli12, CS02, CS06, 
CT05 and LS24) were estimated for each species. Loci were sourced from Ovenden et al. (2006), Keeney and Heist (2003) and Feldheim et al. (2001). Amplifications followed Ovenden et al. (2006). Forward primers had an M13 extension (GAG CGG ATA ACA ATT TCA CAC AGG) at the $5^{\prime}$ end, which allowed the amplicons to be labelled with fluorescent tags (Schuelke 2000). A final extension at $72^{\circ} \mathrm{C}$ for $30 \mathrm{~min}$ was used to ensure complete addition of adenine to the amplicons for consistent allele calling during genotyping. All loci were amplified in separate reactions and then combined for fragment separation according to label colour and fragment size.

Microsatellite fragment separation and scoring were performed using capillary electrophoresis on a MegaBACE 1500 (GE Health Care, Chalfont, UK). The running conditions included a sample injection voltage of $3 \mathrm{KV}$, sample injection time of $45 \mathrm{~s}$ and run voltage of $10 \mathrm{KV}$ with a run time of $75 \mathrm{~min}$. All other parameters were according to the manufacturer's specifications.

Allele scoring was confirmed by calculating the size in base pairs of microsatellite amplicons to two decimal places. Amplicons were allocated to a 'bin' that represented the mean allele size. Scoring of microsatellite alleles was verified by graphical representation of allele size measured to two decimal places against bin size. As expected for dinucleotide loci, alleles were consistently two base pairs apart and there were clear cut-off points between successive allele sizes.

Hardy-Weinberg equilibrium, genotypic linkage disequilibrium and microsatellite allelic distribution across loci for C. tilstoni and C. limbatus were tested using Genepop-on-theweb (Raymond and Rousset 1995). The number of alleles per locus and expected and observed heterozygosity were used to characterise the genetic diversity of microsatellite loci. The standard $F_{\mathrm{ST}}$ approach (Weir and Cockerham 1984) was used to investigate the degree of genetic subdivision between species from microsatellite allelic frequencies, with missing data handled by interpolation. Non-parametric bootstrapping of $F_{\mathrm{ST}}$ values was implemented to estimate $P$-values over 999 random permutations of the dataset. These calculations were performed in GenAlEx ver. 6.1 (Peakall and Smouse 2006).

\section{Results}

\section{Mitochondrial DNA}

MtDNA control region sequence differences were provisionally used to identify blacktip shark samples as either C. tilstoni or C. limbatus. Sequences were aligned and trimmed to 375 base pairs. Sequences from reference $C$. tilstoni $(n=4)$ and C. limbatus $(n=4)$ were characterised by a fixed nucleotide difference at position $234 ; C$. tilstoni had a ' $\mathrm{C}$ ' at this position, whereas C. limbatus haplotypes were 'A'. Single nucleotide polymorphisms did not distinguish $C$. limbatus samples from C. amblyrhynchoides (Table 1).

Additional sequencing of mtDNA COI and ND4 genes identified a further two (COI, Table 2) and 10 (ND4, Table 3) fixed nucleotide differences separating C. tilstoni from C. limbatus samples, confirming the provisional identifications from control region sequence. Fixed differences were also found to distinguish C. amblyrhynchoides from C. tilstoni and C. limbatus samples in COI (one fixed difference at position 130) and ND4 (four fixed differences at positions 55, 136, 137 and 832) gene regions. Haplotype and nucleotide diversities for gene regions are not presented because they are not based on a random population sample.

To test the expectation from the literature that $C$. limbatus was rare in Australian waters, the numbers of $C$. limbatus and $C$. tilstoni samples taken from Australian collection locations were calculated. In Western Australia, sampling was skewed towards C. limbatus; 51 samples were collected compared with 38 for $C$. tilstoni. In the Northern Territory, C. tilstoni samples (59) were more common than those of $C$. limbatus (14), while in Queensland the proportions of the two species were roughly equal $(C$. tilstoni, 54; C. limbatus, 47). No C. tilstoni individuals were found among the 20 blacktip shark samples (C. limbatus and $C$. amblyrhynchoides) analysed from Indonesia.

Distance and parsimony bootstrapping and Bayesian analyses strongly supported $C$. amblyrhynchoides and $C$. tilstoni evolutionary lineages; however, support for the $C$. limbatus lineage was lacking for the distance-based comparison (Fig. 2). Likelihood-based phylogenetic analysis of the concatenated mtDNA sequences found a single tree with a - Ln likelihood score of 3498.34, which placed C. amblyrhynchoides sister to C. limbatus (Fig. 2). Parsimony analysis found six trees of 190 steps, which placed $C$. amblyrhynchoides as either sister to $C$. limbatus or basal to the two blacktip species. Distance analysis reached maximum trees (200) with a minimum evolution score of 0.14603 . All distance trees placed C. amblyrhynchoides basal to the two blacktip species.

A statistical parsimony network (Fig. 3) of mtDNA control region haplotypes emphasised the close relationship between C. tilstoni, C. limbatus and C. amblyrhynchoides. Haplotype CT5 (C. tilstoni) was connected by one mutational step to the C. limbatus haplotype (CL02). Remaining CT haplotypes (CT1-4) were connected to CT5 in a linear string separated by one mutational step. The position of the two C. amblyrhynchoides haplotypes $(\mathrm{CA} 1,2)$ was ambiguous, but their character states were more similar to $C$. limbatus than to $C$. tilstoni haplotypes. Three of the CL control region haplotypes (CL01, 03 and 06) were identical to $C$. limbatus haplotypes sampled from the Indo-Pacific region and Indian Ocean by Keeney and Heist (2006) (Table 1). Western Atlantic Ocean C. limbatus control region haplotypes (Keeney and Heist 2006) were most similar to haplotype CL01 (three mutational steps) and haplotype CA1 (three steps).

\section{Microsatellite loci}

Allele frequencies from five microsatellite loci highlighted the genetic similarity between $C$. tilstoni and $C$. limbatus. There was no evidence for linkage disequilibrium in microsatellite genotype proportions. The observed compared with expected proportion of heterozygotes departed from Hardy-Weinberg equilibrium at loci CS02 and CT05 among C. limbatus samples, and at locus Cli12 in C. tilstoni samples (Table 4). For loci CS02 and CT05 among C. limbatus samples, there were fewer heterozygotes observed than expected. The frequencies of this number of genotypes may have been poorly estimated by the 97 (CS02) and 98 (CT05) C. limbatus individuals assayed in this study. At these loci, there were 18 (CS02) and 13 (CT05) alleles scored for C. limbatus, giving respective totals of 153 


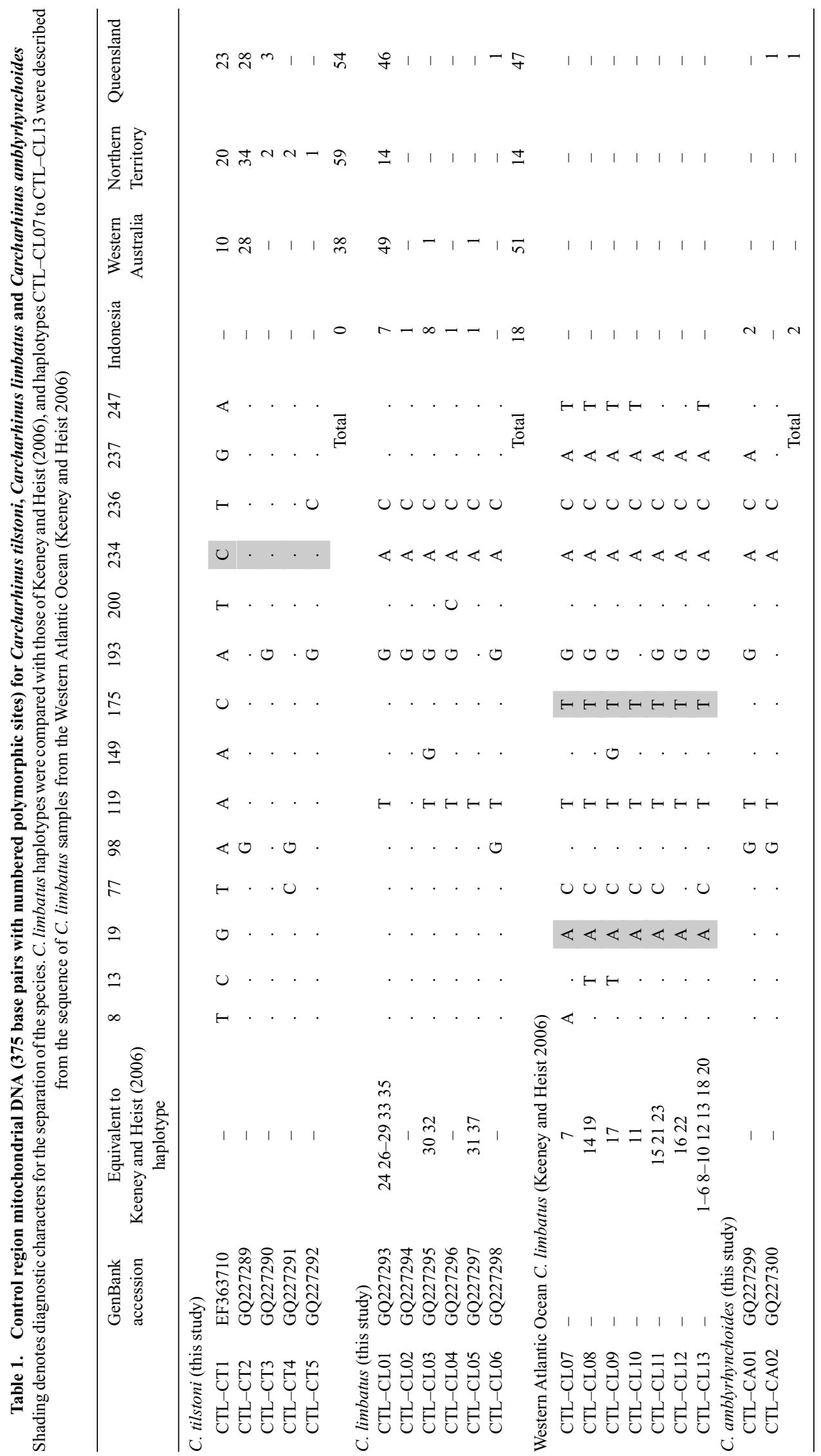



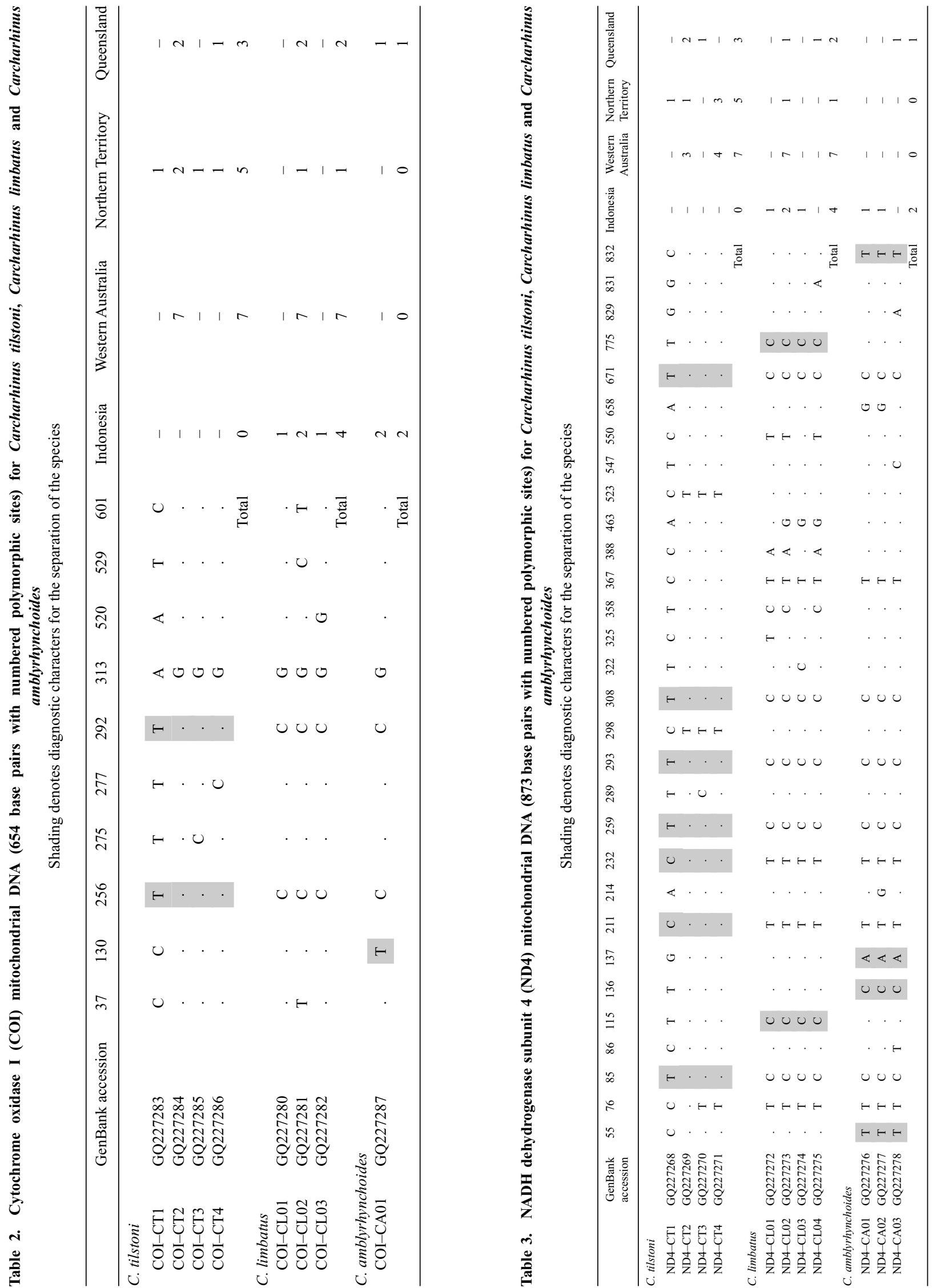
$(=(\mathrm{Na}(\mathrm{Na}-1)) / 2$ where $\mathrm{Na}$ is the number of alleles $)$ and 78 possible heterozygote genotypes per locus. Slightly higher numbers of C. tilstoni were assayed for these loci $(115,103)$ and no departure from equilibrium was recorded. Similarly, genotypes at locus Cli12 among C. tilstoni samples may have departed from Hardy-Weinberg proportions due to small sample sizes as $30 \%$ of the 92 C. tilstoni were unable to be scored for this locus.

There were no fixed allele- frequency differences at five microsatellite loci between $C$. tilstoni and $C$. limbatus, but overall allele frequency differences were significantly different $(P<0.01)$, except for locus Cli12 $(P=0.09)$. For example, the three most frequent alleles at locus CS06 had frequencies of $0.284,0.189$ and 0.405 in C. tilstoni and $0.474,0.278$ and 0.149 in $C$. limbatus (Table 5). The $F_{\mathrm{ST}}$ between the two species was low, but significant $(0.042, P<0.01)$. When the three loci out of Hardy-Weinberg equilibrium (loci Cli12, CS02 and CT05) were omitted, $F_{\mathrm{ST}}$ was $0.062(P<0.01)$.

\section{Discussion}

Species status

This genetic study provides evidence for the specific status of C. tilstoni, C. limbatus and C. amblyrhynchoides as each species is represented by a monophyletic lineage based on mtDNA sequence data from three gene regions. This study and that of Ward et al. (2008) suggest that Australian C. limbatus and C. amblyrhynchoides are more closely related to each other than to $C$. tilstoni. Interestingly, species in the triad appear to be more closely related to each other than they are to C. limbatus from the Western Atlantic Ocean, based on comparisons between our data and that of Keeney and Heist (2006). The original description of the three species reflects a high level of taxonomic expertise given their morphological similarity. There is an urgent need for reliable species identification characters as the C. tilstoni and C. limbatus samples used in this study were all identified in the

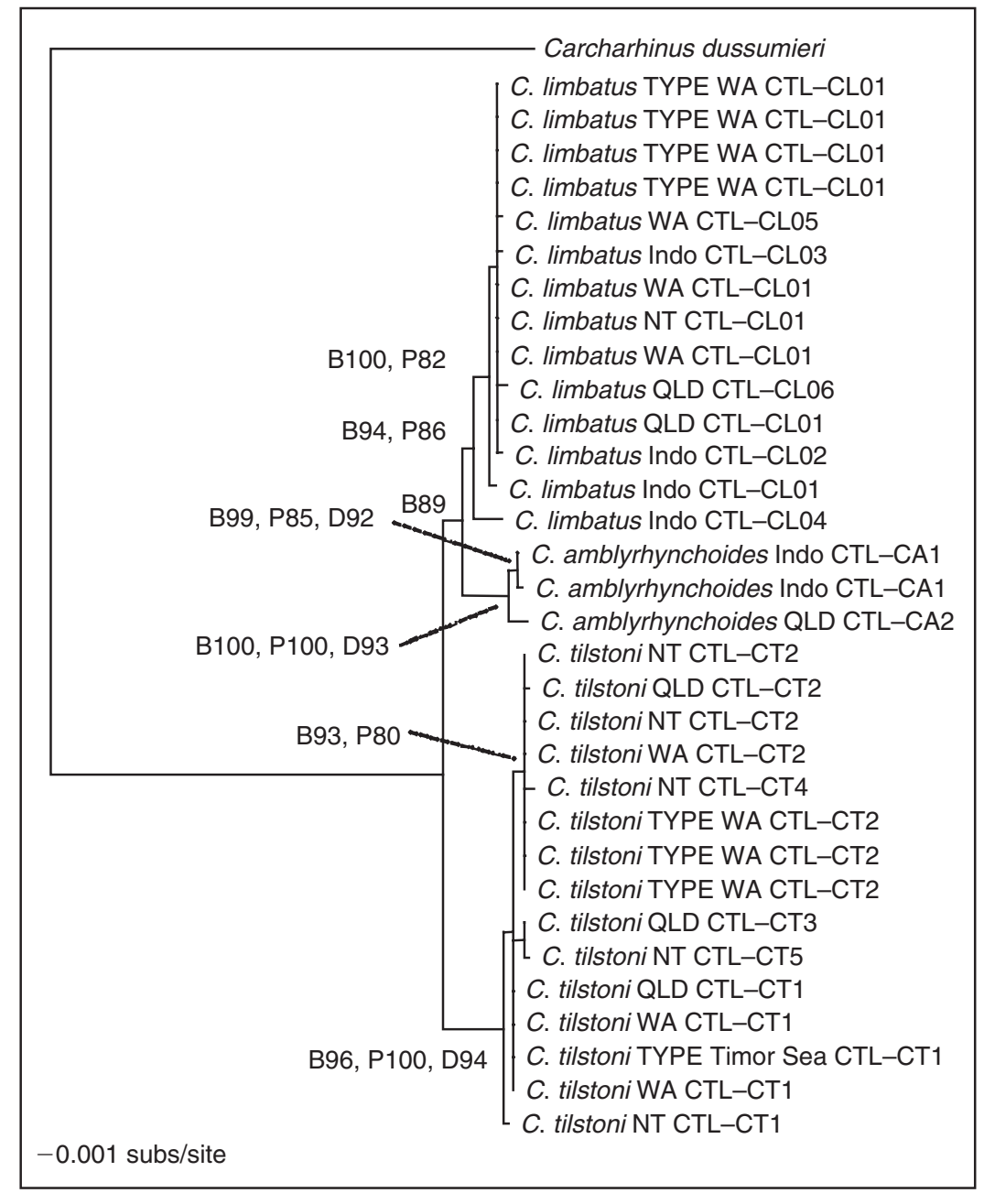

Fig. 2. Maximum likelihood tree of blacktip shark (Carcharhinus tilstoni and C. limbatus) and graceful shark (C. amblyrhynchoides) mitochondrial DNA control region (CTL) haplotypes based on concatenated sequences from control region, COI and ND4 genes using the Tamura-Nei plus gamma model of evolution. Reference samples (TYPE) were used to develop speciesspecific DNA-based identification methods. Branch support is for distance (D), parsimony (P) bootstrapping or Bayesian (B) inference. 


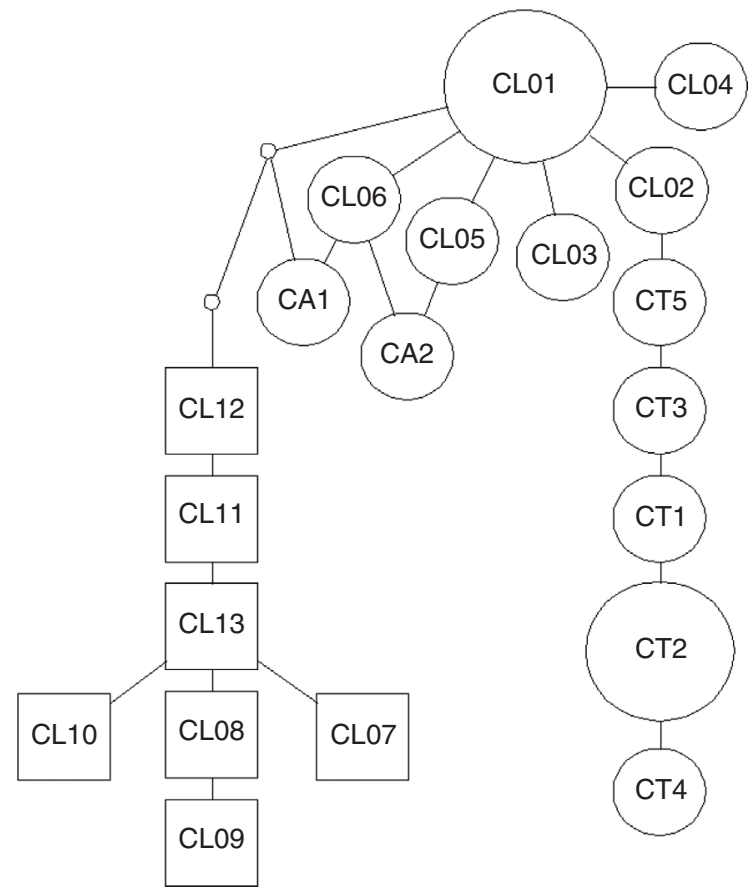

Fig. 3. Statistical parsimony network for Carcharhinus limbatus (CL), Carcharhinus tilstoni (CT) and Carcharhinus amblyrhynchoides (CA) mtDNA control region haplotypes ( 375 base pairs). Haplotypes CL01 and CT2 were the most frequently sampled. Control region haplotypes CL07-13 (squares) are equivalent to those reported by Keeney and Heist (2006) for Carcharhinus limbatus from the Western Atlantic Ocean (Table 1). Small unlabelled circles show missing intermediate haplotypes.

field as C. tilstoni. Ideally, characters would be external, suitable for use in the field and be applicable to all three species. DNA-based identification of specimens could be an aid to the development of suitable morphological characters.

Genetic differentiation at microsatellite loci emphasises the close evolutionary relationship between $C$. tilstoni and C. limbatus. The proportion of overall genetic variation at five microsatellite loci due to the separation of samples into two species $\left(F_{\mathrm{ST}}\right)$ was only 0.042 . In a study of the co-distributed spot-tail shark (C. sorrah), Ovenden et al. (2009) found that pairwise $F_{\mathrm{ST}}$ values for northern Australian populations compared with a central Indonesian population ranged from 0.038 to 0.047 . Thus, the genetic differentiation reported here between two sympatric species (i.e. interspecific, C. tilstoni and C. limbatus) is similar to that reported between two allopatric populations of the same species (i.e. intraspecific, C. sorrah). Nothing is known about the pre- or post-mating isolating mechanisms that presumably operate to prevent hybridisation between co-occurring C. tilstoni and C. limbatus. Likewise, isolating mechanisms that could have led to speciation are unknown. The first step would be to test for the presence of hybrids to confirm reproductive isolation. Maternally inherited mtDNA is an unsuitable marker for hybridisation detection, and fixed differences in allele frequencies were not found between species at microsatellite loci. Intron loci (e.g. Lyons et al. 1997) may provide the most suitable system for hybrid detection. If hybridisation was occurring in some habitats, but not others, this may be reflected in the similarity of microsatellite allele frequencies in locally collected samples. This hypothesis could be tested in future research.

\section{Species occurrence}

This study has confirmed the occurrence of $C$. limbatus in Australian waters but its frequency compared with $C$. tilstoni $(\sim 50: 50)$ is much higher than originally reported $(\sim 1: 300$; Lavery and Shaklee 1991). In the previous study, the two species were identified by pelvic fin colouration, which is now known to be a variable character within $C$. limbatus (Keeney and Heist 2006). The present study has also shown that $C$. tilstoni is likely to be an Australian endemic, as suspected (Compagno et al. 2005; Last and Stevens 2009), as it was not found among the 20 blacktip shark samples from central Indonesia. To delineate the northern extent of $C$. tilstoni, further sampling is needed in the Arafura Sea (southern Papua New Guinea) and the Aru Sea (western Irian Jaya, Indonesia), which are largely contiguous with the shallow tropical seas to the north of Australia.

It is possible that the relative frequency of $C$. tilstoni and C. limbatus has altered through time in northern Australian waters, but an increase in the frequency of $C$. limbatus by two orders of magnitude to the levels reported here is unlikely. A recent comparison of the species composition of the elasmobranch catch in fisheries-independent sampling between the 1980s and mid-2000s showed that $C$. tilstoni has declined in proportion to other shark species in the Queensland Gulf of Carpentaria (N9) and Western Australian north coast (WANCSF) fisheries (Salini et al. 2006). As field identification of C. limbatus and $C$. tilstoni is unreliable, these results probably do not reflect a change in the relative abundance of the species over the 20 -year interval. The reported occurrence of $C$. limbatus only on the NSW coast (Scandol et al. 2008) could be tested using DNA-based species identification methods.

The ratio between the occurrence of $C$. tilstoni and C. limbatus in tropical Australia reported here $(\sim 1: 1)$ needs careful interpretation. First, our samples were not a random sample of both species at the three collection locations. The sampling was potentially biased towards the target species ( $C$. tilstoni), but there is little evidence that field identification methods could accurately target $C$. tilstoni. Interestingly, only low numbers of C. amblyrhynchoides were identified among the samples, suggesting that field identification methods for this species are relatively reliable. Second, samples at the three collection locations were not standardised by fishing method (e.g. long-line $v$. gill-net), fishing location (e.g. inshore or offshore), biological characters (e.g. sex, size) or species identification method used in the field. Our data suggest that there may be geographical variation in the ratio between $C$. tilstoni and C. limbatus, but this needs to be tested. If the geographical variation in ratio is confirmed, it may indicate restrictions to movement between geographical regions, assuming both species occupy similar fine-scale ecological niches.

\section{Fisheries resource management implications}

Commercial fishing practices have the potential to alter the ratio of the two species if they differ in size and growth rate and if they are managed as a single species. For example, fixed-mesh-size 
Table 4. The sample size (n), number of microsatellite alleles per locus (Na), average observed homozygosity (Ho) and expected (He) and unbiased (UHe) heterozygosity and fixation index $(F)$ for Carcharhinus tilstoni and Carcharhinus limbatus Signif. $=$ significant deviations $(P=0.01)$ from Hardy-Weinberg equilibrium are noted by *

\begin{tabular}{|c|c|c|c|c|c|c|c|c|}
\hline Species & Locus & $n$ & $\mathrm{Na}$ & Ho & $\mathrm{He}$ & UHe & $F$ & Signif. \\
\hline \multirow[t]{5}{*}{ C. tilstoni } & Cli12 & 92 & 6 & 0.41 & 0.53 & 0.53 & 0.22 & $*$ \\
\hline & $\mathrm{CS} 02$ & 115 & 23 & 0.88 & 0.91 & 0.91 & 0.03 & \\
\hline & $\mathrm{CS} 06$ & 111 & 8 & 0.71 & 0.71 & 0.72 & 0.00 & \\
\hline & CT05 & 103 & 13 & 0.73 & 0.75 & 0.75 & 0.03 & \\
\hline & $\mathrm{LS} 24$ & 104 & 8 & 0.61 & 0.63 & 0.63 & 0.03 & \\
\hline \multirow[t]{5}{*}{ C. limbatus } & Cli12 & 95 & 6 & 0.46 & 0.48 & 0.49 & 0.04 & \\
\hline & $\mathrm{CS} 02$ & 97 & 18 & 0.70 & 0.91 & 0.91 & 0.23 & $*$ \\
\hline & $\mathrm{CS} 06$ & 97 & 7 & 0.58 & 0.67 & 0.67 & 0.14 & \\
\hline & СТ05 & 98 & 13 & 0.80 & 0.88 & 0.88 & 0.09 & $*$ \\
\hline & LS24 & 100 & 7 & 0.61 & 0.63 & 0.64 & 0.04 & \\
\hline
\end{tabular}

Table 5. Allele frequencies for five microsatellite loci for Carcharhinus tilstoni and Carcharhinus limbatus

Frequencies of rare alleles were pooled. Number of samples genotyped per locus per species is in bold

\begin{tabular}{|c|c|c|c|}
\hline Locus & Allele & C. tilstoni & C. limbatus \\
\hline \multirow[t]{6}{*}{$\mathrm{CS} 02$} & & 115 & 97 \\
\hline & 1 & 0.065 & 0.160 \\
\hline & 2 & 0.026 & 0.144 \\
\hline & 3 & 0.091 & 0.108 \\
\hline & 4 & 0.217 & 0.088 \\
\hline & Rare & 0.600 & 0.500 \\
\hline \multirow[t]{5}{*}{ CS06 } & & 111 & 97 \\
\hline & 1 & 0.284 & 0.474 \\
\hline & 2 & 0.189 & 0.278 \\
\hline & 3 & 0.405 & 0.149 \\
\hline & Rare & 0.122 & 0.098 \\
\hline \multirow[t]{6}{*}{ СТ05 } & & 103 & 98 \\
\hline & 1 & 0.204 & 0.199 \\
\hline & 2 & 0.432 & 0.153 \\
\hline & 3 & 0.102 & 0.143 \\
\hline & 4 & 0.044 & 0.107 \\
\hline & Rare & 0.218 & 0.398 \\
\hline \multirow[t]{4}{*}{ Cli12 } & & 92 & 95 \\
\hline & 1 & 0.533 & 0.637 \\
\hline & 2 & 0.429 & 0.332 \\
\hline & Rare & 0.038 & 0.032 \\
\hline \multirow[t]{5}{*}{ LS24 } & & 104 & 100 \\
\hline & 1 & 0.380 & 0.530 \\
\hline & 2 & 0.471 & 0.245 \\
\hline & 3 & 0.072 & 0.155 \\
\hline & Rare & 0.077 & 0.070 \\
\hline
\end{tabular}

commercial gill-nets could selectively remove larger individuals. C. tilstoni has been reported to be $60 \mathrm{~cm}$ long at birth and grows to $200 \mathrm{~cm}$ and $C$. limbatus ranges from 40 to $60 \mathrm{~cm}$ at birth and grows to $250 \mathrm{~cm}$ (Last and Stevens 2009). However, Salini et al. (2006) gave both species similar ranking in susceptibility to fishing pressure. There is an urgent need to confirm this data with larger sample sizes across northern Australian fishing zones and to conduct analyses of age at reproductive maturity and growth rates from catches in various fishing sectors on specimens whose identity is confirmed either with DNA or newly derived morphological characters.

This study contributes to the knowledge needed by fisheries managers for the sustainable harvest of whaler sharks in northern Australia and Indonesia. We have shown that the abundance of $C$. limbatus compared with C. tilstoni in northern Australian waters is considerably higher than previous estimates of $1: 300$ (Stevens and Wiley 1986; Lavery and Shaklee 1991). This study has shown that $C$. limbatus is equally as frequent as $C$. tilstoni, and consequently the tropical Australian shark fishery may take equal numbers of both species. This raises concern for the sustainability of this previously unrecognised component of the tropical Australian shark fishery and highlights the need for more detailed knowledge of its susceptibility to commercial fishing. This study provides DNA-based tools for species identification but new field-based morphological identification methods are urgently needed.

\section{Acknowledgements}

We sincerely thank tissue sample collectors including Rik Buckworth, Dharmadi, Fahmi, Jenny Giles, Rory McAuley, Stirling Peverell, Richard Pillans, Colin Simpendorfer, Jason Stapely, Chris Tarca, Steve Taylor, David Welch and William White. Malcolm Dunning, Warwick Nash, Wayne Sumpton and two anonymous reviewers kindly provided comments on earlier versions of the text. The Australian Fisheries Research and Development Corporation made financial contributions to this study.

\section{References}

Arevalo, E., Davis, S., and Sites, J. J. (1994). Mitochondrial DNA sequence divergence and phylogenetic relationships among eight chromosome races of the Sceloporus grammicus complex (Phrynosomatidae) in central Mexico. Systematic Biology 43, 387-418.

Clement, M., Posada, D., and Crandall, K. A. (2000). TCS: a computer program to estimate gene genealogies. Molecular Ecology 9, 1657-1659. doi:10.1046/J.1365-294X.2000.01020.X

Compagno, L. J. V., Dando, M., and Fowler, S. (2005). 'Sharks of the World.' 1 st edn. (Princeton University Press: Princeton, NJ.)

Cunningham, C. W. (1997). Is congruence between data partitions a reliable predictor of phylogenetic accuracy? Empirically testing an iterative 
procedure for choosing among phylogenetic methods. Systematic Biology 46, 464-478.

Feldheim, K. A., Gruber, S. H., and Ashley, M. V. (2001). Population genetic structure of the lemon shark (Negaprion brevirostris) in the western Atlantic: DNA microsatellite variation. Molecular Ecology 10, 295-303. doi:10.1046/J.1365-294X.2001.01182.X

Huelsenbeck, J. P., and Ronquist, F. (2001). MRBAYES: Bayesian inference of phylogenetic trees. Bioinformatics 17, 754-755. doi:10.1093/ BIOINFORMATICS/17.8.754

Inoue, J. G., Miya, M., Tsukamoto, K., and Nishida, M. (2001). A mitogenomic perspective on the basal teleostean phylogeny: resolving higherlevel relationships with longer DNA sequences. Molecular Phylogenetics and Evolution 20, 275-285. doi:10.1006/MPEV.2001.0970

Keeney, D. B., and Heist, E. J. (2003). Characterization of microsatellite loci isolated from the blacktip shark and their utility in requiem and hammerhead sharks. Molecular Ecology Notes 3, 501-504. doi:10.1046/J.14718286.2003.00492.X

Keeney, D. B., and Heist, E. J. (2006). Worldwide phylogeography of the blacktip shark (Carcharhinus limbatus) inferred from mitochondrial DNA reveals isolation of western Atlantic populations coupled with recent Pacific dispersal. Molecular Ecology 15, 3669-3679. doi:10.1111/ J.1365-294X.2006.03036.X

King, M. (2007). 'Fisheries Biology, Assessment and Management.' 2nd edn. (Blackwell: Oxford.)

Last, P. R., and Stevens, J. D. (2009). 'Sharks and Rays of Australia.' 2nd edn. (CSIRO Publishing: Melbourne.)

Lavery, S. (1992). Electrophoretic analysis of phylogenetic relationships among Australian carcharhinid sharks. Australian Journal of Marine and Freshwater Research 43, 97-108. doi:10.1071/MF9920097

Lavery, S., and Shaklee, J. B. (1991). Genetic evidence for separation of two sharks Carcharhinus limbatus and C. tilstoni from northern Australia. Marine Biology 108, 1-4. doi:10.1007/BF01313464

Lindenmayer, D., and Burgman, M. (2005). 'Practical Conservation Biology.' (CSIRO Publishing: Melbourne.)

Lyons, L. A., Laughlin, T. F., Copeland, N. G., Jenkins, N. A., Womack, J. E., et al. (1997). Comparative anchor tagged sequences (CATS) for integrative mapping of mammalian genomes. Nature Genetics 15, 47-56. doi:10.1038/NG0197-47

Ovenden, J. R., Broderick, D., and Street, R. (2006). Microsatellite primers for two carcharinid sharks (Carcharinus tilstoni and C. sorrah) and their usefulness across a wide range of shark species. Molecular Ecology Notes 6, 415-418. doi:10.1111/J.1471-8286.2005.01254.X

Ovenden, J. R., Kashiwagi, T., Broderick, D., Giles, J., and Salini, J. P. (2009). The extent of population genetic subdivision differs among four co-distributed shark species in the Indo-Australian archipelago. BMC Evolutionary Biology 9, 40. doi:10.1186/1471-2148-9-40

Pardini, A. T., Jones, C. S., Noble, L. R., Kreiser, B., Malcolm, H., et al. (2001). Sex-biased dispersal of great white sharks - in some respects, these sharks behave more like whales and dolphins than other fish. Nature 412, 139-140, doi:10.1038/35084125
Peakall, R., and Smouse, P. E. (2006). GenAlEx 6: genetic analysis in Excel. Population genetic software for teaching and research. Molecular Ecology Notes 6, 288-295. doi:10.1111/J.1471-8286.2005.01155.X

Posada, D., and Crandall, K. A. (1998). Modeltest: testing the model of DNA substitution. Bioinformatics (Oxford, England) 14, 817-818. doi:10.1093/BIOINFORMATICS/14.9.817

Raymond, M., and Rousset, F. (1995). GENEPOP (version 1.2): population genetics software for exact tests and ecumenicism. The Journal of Heredity 86, 248-249.

Salini, J. P., McAuley, R., Blaber, S. J. M., Buckworth, R., Chidlow, J., et al. (2006). Northern Australian sharks and rays: the sustainability of target and bycatch species. Commonwealth Scientific and Industrial Organisation, FRDC Project number 2002/064, Brisbane.

Scandol, J., Rowling, K., and Graham, K. (Eds) (2008). Whaler sharks (Carcharhinus spp.). In 'Status of Fisheries Resources in NSW 2006/07'. pp. 305-308. (NSW Department of Primary Industries, Sydney.)

Schuelke, M. (2000). An economic method for the fluorescent labeling of PCR fragments. Nature Biotechnology 18, 233-234. doi:10.1038/72708

Stevens, J., and Wiley, P. (1986). Biology of two commercially important carcharhinid sharks from northern Australia. Australian Journal of Marine and Freshwater Research 37, 671-688. doi:10.1071/MF9860671

Swofford, D. L. (2002). 'PAUP*: Phylogenetic Analysis Using Parsimony (*and Other Methods).' ver. 4.0b10. (Sinauer Associates: Sunderland, MA.)

Thompson, J. D., Gibson, T. J., Plewniak, F., Jeanmougin, F., and Higgins, D. G. (1997). The CLUSTAL_X windows interface: flexible strategies for multiple sequence alignment aided by quality analysis tools. Nucleic Acids Research 25, 4876-4882. doi:10.1093/NAR/25.24.4876

Ward, R. D., Zemlak, T. S., Innes, B. H., Last, P. R., and Hebert, P. D. N. (2005). DNA barcoding Australia's fish species. Philosophical Transactions of the Royal Society B 360, 1847-1857. doi:10.1098/RSTB.2005.1716

Ward, R. D., Holmes, B. H., White, W. T., and Last, P. R. (2008). DNA barcoding in Australasian chondrichthyans: results and potential uses in conservation. Marine and Freshwater Research 59, 57-71. doi:10.1071/ MF07148

Weir, B. S., and Cockerham, C. C. (1984). Estimating $F$-stastistics for the analysis of population structure. Evolution 38, 1358-1370. doi:10.2307/ 2408641

White, W. T., Last, P. R., Stevens, J. D., Yearsley, G. K., Fahmi, and Dharmadi (2006). 'Economically Important Sharks and Rays of Indonesia.' (Australian Centre for International Agricultural Research: Canberra.)

Whitley, G. P. (1950). A new shark from north-western Australia. Western Australian Naturalist 2, 100-105.

Manuscript received 19 June 2009, accepted 24 August 2009 